\title{
O conteúdo jurídico da responsabilidade penal*.
}

\author{
Nelson Ferreira Leite
}

\begin{abstract}
Diz-se que alguém é responsável criminalmente, pela prática de um ato reputado delituoso, quando deve responder por êle perante o poder social. A violação da norma penal cria para o Estado uma "pretensão punitiva" (strafanspruch). Mas, a responsabilidade pressupõe, como condição fundamental, certas condições sem as quais ela não pode ocorrer. $€$ indispensável que o agente a quem se atribui a prática do ato punivel seja imputável, isto é, que esteja em condições de se lhe poder atribuir a responsabilidade pela infração.

A imputabilidade significa, assim, a possibilidade de se atribuir a determinada pessoa a culpa (lato sensu) de certo procedimento. Imputabilidade, pois, significa capacidade para a culpa.

Essa capacidade, entretanto, pressupõe a existência de dois fundamentais requisitos: a) que tenha o agente atingido certo grau de desenvolvimento intelectual; b) que possua liberdade de vontade.

Com relação ao primeiro requisito, as opiniões são unânimes. 'Tanto na doutrina como nas legislações se reconhece, pacìficamente, que o indivíduo precisa contar com certo grau de maturidade intelectual para ter uma exata representação das conseqüências dos seus atos no mundo externo. Só após um completo desenvolvimento

* Trabalho apresentado, em dezembro de 1962, no Curso de Especialização da Faculdade de Direito, cadeira de Direito Penal Comparado.
\end{abstract}


intelectual é que o individuo estará em condições de poder apreciar a ilicitude da sua conduta.

Já com relação ao segundo requisito — a liberdade da vontade - as dissenções são profundas e irreconciliáveis. Para muitos a liberdade da vontade se confunde com o livre arbítrio, que consiste na faculdade de escolher ou não escolher, sem outro motivo que a própria vontade.

Para outros, entretanto, a liberdade nada mais significa do que o poder que tem o homem de determinar-se por si mesmo, de acôrdo com os motivos e a própria individualidade. São êstes os partidários da liberdade psicológica da vontade e constituem o grupo dos que se filiam à escola determinista ${ }^{1}$.

As controvérsias, nesse ponto, são irredutíveis. Por isso já se tem salientado que a questão da liberdade da vontade transcende ao âmbito do Direito Penal, por ser de índole puramente filosófica. De tal forma, não pode constituir objeto de investigação jurídica.

Interessante, portanto, será fazer-se uma análise do problema da responsabilidade, tal como se tem apresentado no campo do Direito Penal, e das soluções que a êsse respeito, modernamente, se têm proposto para a controvérsia.

Desde muito cedo, a humanidade começou castigando os autores das infrações que considerava nocivas à comunidade. Só mais tarde, porém, é que se preocupou de indagar se podia fazê-lo, e em que medida.

Essa simples dúvida já constitui avançado progresso. Não só porque revela um grau bem mais adiantado de reflexão, como também porque torna nítida a idéia de que o castigo pelo castigo não pode constituir fundamento para o ministério repressivo.

Em épocas passadas havia uma crença popular na responsabilidade dos animais e, por isso, eram êles tidos

1. A. J. Costa e Silva, Código Penal dos Estados Unidos do Brasil (de 1890), vol. I, p. 132. 
como possíveis sujeitos ativos de crimes. Quando um animal ofendia uma pessoa, era castigado como se fôsse um sêr humano.

Como conseqüência dessa maneira de entender, durante a Idade Média, muitos animais foram condenados por delitos praticados contra a pessoa. Várias classes de penas the foram aplicadas, sendo a mais freqüente a pena de morte.

Aliás, é curioso que essa crença se estendesse até mesmo ao reino das plantas, sendo elas consideradas como responsáveis pelos danos causados às pessoas. Assinala-se, a êsse respeito, que o próprio Jesus Cristo, aparentemente, agiu debaixo dessa crença, quando amaldiçoou a figueira estéril da Betânia, por não proporcionar alimentos aos homens ${ }^{2}$.

Entre os povos primitivos, não faltam exemplos de punição sem culpa. A religião hebraica, ao lado da teocracia política, ameaçava com penas não só os culpados como os seus filhos e os filhos dos seus filhos, até a sétima geração.

$O$ fado, na imaginação dos antigos helenos, feria, às cegas, tanto o culpado como o inocente. Segundo o direito sagrado de Roma, a infração cometida por acaso provocava, do mesmo modo que a intencional, a cólera dos deuses, que devia ser aplacada pela expiação. Foi por influência dos moralistas gregos que o Direito Romano considerou, cada vez mais, como elemento decisivo, a vontade anti-jurídica.

Assim como não repugnava à concepção religiosa que os pecados dos pais recaíssem sôbre os filhos e netos, assim como na tragédia dos antigos o destino fatal e, na literatura moderna, a Jei da herança, suplantam a culpabilidade, assim também o primitivo direito de todos os povos conheceu a responsabilidade sem culpa ${ }^{3}$.

O delito considerado apenas objetivamente, era visto, simplesmente, como ação modificadora do mundo exterior. Só se levava em conta a sua "parte objecti", configurada no

2. M. PARMELle, Criminologia, ed. esp., p. 11.

3. Franz Von List, Tratado de Derecho Penal, ed. esp. vol. 2, p. 390 . 
"damnum". O fato volitivo passava a um plano secundário e o conceito de delito se exauria nos limites da ofensa.

Essa noção objetiva da responsabilidade predominou, de um modo geral, até o final do século xvir. O próprio Código Penal francês de 1810 fundava-se em um sistema de responsabilidade objetiva, concretizada no mal externo que havia sido produzido e não pelo estado psicológico do autor da infração.

Dêsse modo, o princípio, que hoje nos parece natural, de que a culpabilidade é um caráter essencial do delito e que, sem ela, não é possivel impor pena alguma, é o resultado de uma longa evolução, até hoje não completamente desenvolvida.

Só gradualmente a idéia da infração vai tomando, em si mesma, a característica de culpabilidade; e, pelo aperfeicoamento dessa doutrina, se pode medir o progresso de todo o Direito Penal ${ }^{4}$.

Aos poucos vai se formando, no Direito Romano, o conceito de inimputabilidade dos "infans" (menores de sete anos) e da irresponsabilidade dos portadores de moléstias mentais, até que, com o Direito Canônico e com o Direito Estatutário, se inicia o desenvolvimento do conceito de dolo e culpa, através do qual a consideração subjetiva do crime entra no Direito Penal ${ }^{5}$. Mas, é com o aparecimento da Escola do Direito Natural e com a Filosofia Iluminista que essas noções se concretizam, a ponto de formarem um corpo de doutrina.

O direito natural, colocando-se acima do direito positivo, punha êste em constante problemática, criando a exigência de uma sistematização jurídica racional. Essas construções tinham como modêlo a geometria ("more geometrico") e seguiam o método dedutivo próprio da dogmática.

4. Franz VoN LIST, ob. cit., vol, 2, p. 390.

5. Vicenzo Manzini, Tratatto di Diritto Penale, vol. I, p. 584. 
De outro lado, por sua vocação individualista, o direito natural era levado a plasmar-se sôbre o Direito Romano, que havia atingido a mais alta perfeição dogmática. Dêsse modo cabe a essa Escola a iniciativa de trazer soluções especiais ao direito punitivo, a começar pela imputabilidade e pelos problemas relativos à legítima defesa.

A Escola do Direito Natural encontra o seu fundamento jurídico no contrato, de modo que o direito de punir é por ela considerado como uma cessão à sociedade do direito de defesa pessoal que, no estado natural, compete ao indivíduo. Posteriormente, a Filosofia Iluminista, seguindo os mesmos princípios, vai encontrar, no campo do Direito Penal, a sua expressão culminante, na obra de Cesare Beccaria, Dei delitti e delle pene.

Conquanto as idéias expostas nessa obra não sejam de todo originais, o seu enorme sucesso, mais do que o seu valor científico, deveu-se à sua atualidade política, transplantando para o Direito Penal o influxo das idéias liberais que haviam atingido o seu maior desenvolvimento.

Mais tarde, Giandomenico Romagnosi, com a publicação de sua obra Genese del Diritto Penale, veio dar fortes delineamentos ao conceito de imputabilidade, fundada na responsabilidade moral. Seguindo a filosofia dominante, admitia êle um direito de punir do indivíduo preexistente ao contrato, direito êsse cedido à sociedade com o fim de preservar a felicidade comum.

Todavia, a sua teoria não envereda para o materialismo determinista, mas se orienta para as profundezas da alma humana, investigando os motivos que precedem a ação delituosa. A sua teoria de que a pena vale como contra estímulo (controspinta) ao estímulo criminoso (spinta) demonstra o seu interêsse pelo aspecto psicológico do delito.

Romagnosı não nega, pois, a liberdade e, pelo contrário, a coloca como fundamento de todo o direito. Por isso define o delito como um ato completado com inteligência e liberdade. A imputabilidade moral é considerada como pressuposto irrevogável da responsabilidade juridica: 
"senza l'imputabilità morale non può existere responsabilità penale".

Estava, assim, perfeitamente discriminado o princípio da responsabilidade moral, que serviria de motivo determinante dos postulados da Escola Clássica. Essa Escola vai encontrar a sua expressão definitiva, na Itália, na obra de Francesco Carrara. Embora sem a originalidade de alguns de seus predecessores, o que distingue êsse autor é um extraordinário poder de lógica jurídica, a fôrça de argumentação com que expõe o seu admirável Programma, num trabalho extraordinário de sistematização que o consagrou como um dos maiores penalistas de todos os tempos.

Segundo a Escola Clássica, uma vez que os indivíduos agem conscientemente, têm inteira responsabilidade pelos seus atos e, por isso, são moralmente imputáveis. A liberdade de opção, a liberdade de escolha entre o bem e o mal, os fazem responsáveis e, dessa forma, devem sofrer as conseqüências dos seus atos. $O$ crime não é um ente de fato, mas um ente jurídico, uma relação entre o delinqüente e a lei escrita. É uma expressão inteiramente formal, de modo que a pena se apresenta como um castigo, decorrência lógica e merecida da ação de quem, podendo e devendo, não quis evitar o mal praticado.

Nessa conformidade, a conduta objetivamente ilícita de que proveio a lesão a interêsse penalmente tutelado só será considerada, isto é, só será delituosa e punivel, se contiver o coeficiente subjetivo de culpabilidade. E como falte ao vocabulário jurídico um têrmo que exprima genèricamente o elemento subjetivo do crime, de forma a abranger em seu conteúdo o querer doloso e culposo, adota-se o têrmo culpabilidade para designar o elemento psicológico do delito ${ }^{6}$.

Integra-se, assim, no campo do Direito Penal, o conceito de culpabilidade, que nada mais é do que o nexo

6. J. Frenerico MARQUes, Curso de Direito Penal, vol. $2 .^{\circ}$, p. 158. 
subjetivo que liga o delito ao seu autor. Decompondo-se idealmente o delito nos seus dois elementos - o subjetivo, também chamado psíquico, e o objetivo, também chamado físico ou externo, a culpabilidade integra o primeiro dêsses elementos, coincidindo com êle ${ }^{7}$.

Contudo, cumpre observar que o conceito de culpabilidade, asssim considerado, não coincide exatamente com o de responsabilidade. Esta é da conseqüência penal atribuída a pessoa a quem se estabeleceu dever responder pelo crime. E a obrigação de sofrer as conseqüências do delito ${ }^{8}$.

De tal forma, a responsabilidade será uma decorrência da imputabilidade, mas nem sempre obrigatória porque alguém pode ser imputável, sem ser responsável ${ }^{9}$.

Contudo, o principio da responsabilidade moral, sustentado pela Escola Clássica, haveria de sofrer um forte impacto da Escola Positiva, sua acérrima opositora.

$\mathrm{Na}$ segunda metade do século passado, Benedito AgosTINHO MoREL, em duas obras notáveis, uma sôbre a degenerescência (1857) e outra sôbre moléstias mentais (1870), estabeleceu as premissas da teoria da degeneração, criando o conceito das chamadas psicoses degenerativas. Esses estudos deram origem à concepção da Escola Antropológica, iniciada por Cesare Lombroso, que atribuía à herança o tipo biológico do delinqüente. A essa idéia aderiram, desde logo, Ferri e Garofalo, orientando para as ciências sociais o antropologismo inicial de Lombroso.

Segue essa nova Escola o método indutivo de observação e de experimentação. Recomenda que o autor de cada delito seja estudado em tudo o que possa constituir fenomenologia própria a orientar a gênese do delito, sua terapêutica e sua profilaxia.

7. Basileu Garcia, Instituições de Direito Penal, tomo I, vol. I, p. 248, $1 .^{2}$ edição.

8. Remo PañNaIn, La strutura del reato, p. 59.

9. BASILEU GaRCIA, Causalidade material e psíquica in Revista Forense, vol. Xc, p. 593. 
O delinqüente age independentemente de sua vontade, forçado por circunstâncias inerentes à sua estrutura física e psíquica ou do meio. Mas a sua atividade é prejudicial, abalando a coletividade, perante a qual é responsável como perigoso. $O$ crime fenômeno natural e social, foi o sintoma revelador do mal do qual seu autor é prêsa. A responsabilidade, portanto, à luz dessa Escola, é social. A pena não é um castigo ou medida aflitiva, desde que não se admite a responsabilidade de querer, agindo o indivíduo ante imperativos internos e externos, mas é defesa social. A sua medida é dada, não pelo crime em si, mas pelo criminoso.

Por isso há, ainda hoje, uma tendência para sustentar a possibilidade de se prescindir da relação psicológica, dando-se maior relêvo ao ato danoso e à necessidade de uma defesa da sociedade, em face da causa produtiva do crime.

Mas, êsse entendimento não é preponderante. Com ef eito, difìcilmente se poderá conceber, de maneira absoluta, a teoria da responsabilidade social, legal ou objetiva, fundada na simples relação de causalidade material, sem reconhecer o fundamento da responsabilidade no elemento psíquico. Nem mesmo nas legislações de países autoritários conseguem banir de seus estatutos repressivos o fundamento da responsabilidade ético-jurídica.

Acresce, ainda, que a teoria da responsabilidade social, levada às suas últimas conseqüências, tende a dar maior ênfase intimidativa ao direito repressivo e, com facilidade, descamba do conceito de "difesa sociale", na concepção de FERri, para o conceito de "difesa propria dello Stato", a exemplo das legislações autocráticas, onde o delinqüente aparece, antes de mais nada, como inimigo do regime e do Estado, e a sua intimidação representa a mais importante função do poder penal.

Ademais, a idéia de repressão, não se fixando nos seus justos limites, pode dar lugar a adoção de penas excessivamente rigorosas, e isto seria um grave êrro já que, sendo elas em extremo severas, tornam-se de aplicação mais problemática e prejudicam o objetivo da intimidação. 0 
próprio princípio da legalidade dos delitos pode sofrer sério golpe quando se leva muito longe o conceito de responsabilidade, como ocorre em certas legislações: "Est aussi consideré comme dèlite tout acte socialement dangereux qui, bien qu'il ne soit pas expressèment indiqué par la loi, se rapproche par son caractére de l'un des délits prevus"10.

Por isso tem surgido entre os penalistas uma forte reação contra o que se costuma chamar em doutrina de responsabilidade pelo resultado. Daí o acolhimento geral do princípio que estabelece que “personne n'est punissable à raison des consequences de ses actes que dans mesure de celles qu'il a prévues ou pu prévoir."

É com certa relutância que se tem admitido, nos crimes qualificados pelo resultado, o princípio da responsabilidade objetiva como medida de política criminal. Mas, mesmo nesses casos, há quem exija, para a caracterização do delito, pelo menos, um certo grau de previsibilidade do evento danoso, por parte do agente.

Atualmente, raras são as legislações que, influenciadas pela Escola Clássica, subordinam a responsabilidade delituosa à condição de ser livre (nesse sentido, notadamente, o Código Penal alemão, de 1871, $\S 51$, o Código Penal italiano, de 1889, art. 64, e, mais recentemente, o Código Penal venezuelano de 1926, art. 62).

Os autores dos Códigos modernos, sistemàticamente, se abstém de usar essa expressão. A fórmula mais freqüente consiste em exigir, para que o ato visado seja punivel, que tenha sido cometido com consciência e vontade, a exemplo do Código Penal italiano, de 1930, art. 42, do Código Penal polonês, de 1932, art. 17 e do Código Penal alemão, modificado pela Lei de 24 de novembro de $1933^{11}$.

Tem-se afirmado que a negação ou a afirmação do livre arbítrio é problema metafísico que escapa à demons-

10. Marc ANCEL, Les Codes Pénaux Européens, vol. I, p. 275.

11. H. DONN̄EDIEU DE VABRES, Traité de Droit Criminel et de Legislation Pénale Comparée, p. 147. 
tração científica e que, portanto, não pode constituir objeto de legislação penal.

Nem por isso, entretanto, as legislações modernas deixam de exigir o elemento consciência e vontade como fundamento do direito punitivo. O Código Penal italiano, por exemplo, considera indispensável para ocorrer a imputabilidade concreta "una azione od omissione comessa com coscienza e voluntà."

O Código Penal soviético, com a orientação interpretativa baixada dos Soviets em 1958, conquanto consagre o principio da responsabilidade legal, não discrepa dessa orientação, considerando penalmente irresponsáveis os agentes que, ao tempo da ação ou da omissão, se encontravam em estado de não imputabilidade moral.

É que, "si la existencia del ato socialmente peligroso es la base objetiva de la responsabilidad penal, la existencia de la falta es la base subjetiva".

"La essencia de la falta reside en la actitud psiquica del individuo bajo forma intencional ou bajo forma de negligencia, frente a un acto socialmente peligroso cometido por él, condenado por el Estado y el pueblo sovietico. Sin falta no hay delito ni sanción ${ }^{12}$.

O moderno e notável anteprojeto de Código Penal argentino, de autoria de Sebastian Soler, estatui, em seu art. 18: "De ninguna consecuencia de la acion será responsable el autor ou el participe de un hecho, si con respecto a ela no ha obrado, a lo menos, culposamente".

Sob êsse critério, o exame psíquico que no criminoso precede a ação física, põe à luz a existência de quatro tipos psicológicos de delinqüentes: 1) voluntários ou dolosos; 2) involuntários ou culposos; 3) conscientes, mas de vontade imatura ou doente; 4) inconscientes (por infância, idiotia, automatismo psíquico, delírio com doença mental ou comum) ${ }^{13}$.

12. Henri Chambre, El marxismo en la Union Sovietica, p. 174.

13. Henrique Ferri, Direito Criminal, ed. port., p. 219. 
Segundo essa divisão, acolhida em linhas gerais pelo nosso atual Código Penal, estão integralmente sujeitos à sanção penal os indivíduos incluídos no primeiro e no segundo grupo. Os do terceiro têm responsabilidade atenuada e os do último grupo escapam completamente à esfera punitiva, em virtude de causas que determinam a exclusão de sua responsabilidade, no campo do Direito Penal.

As causas que suprimem a responsabilidade e que, por conseqüência, afastam a pena, são de duas categorias. Umas, como nos casos de alienação mental, residem na própria pessoa do agente: têm um caráter individual e denominamse causas de não imputabilidade ou dirimentes. Outras resultam de fatos exteriores, como ocorre nos casos de legitima defesa, e denominam-se causas justificativas. Mas, destas, não tratamos no presente ensaio, que se limita, ùnicamente, a um determinado aspecto da parte subjetiva do delito.

Três são os critérios, acolhidos pelas legislações penais, para se resolver o problema da responsabilidade subjetiva: o biológico, o psicológico e o bio-psicológico ou misto.

0 primeiro encontra a sua expressão típica no Código Penal francês para o qual "Il n'y a ni crime ni delit, lorsque le prévenu était en état de démence au temps de l'action..."

O segundo método atende tão só ao estado psicológico do agente no momento da ação, independentemente de se cogitar de qualquer enfermidade mental. Seguia êsse critério o nosso Código Penal de 1890, quando dirimia a responsabilidade no caso de completa perturbação dos sentidos e da inteligência. Inspirava-se, nesse passo, no Código Penal bávaro de 1813.

Idêntico critério foi seguido pelo Código Penal português de 1886, estabelecendo no seu artigo 26: "sòmente podem ser criminosos os indivíduos que têm a necessária inteligência e liberdade".

Esses dois sistemas, sem dúvida, apresentam graves inconvenientes. $O$ primeiro porque, como salienta a Expo- 
sição de Motivos que antecede o nosso Código Penal, admite apriorìsticamente um nexo de causalidade constante entre o estado mental patológico do agente e o crime: coloca os juízes na absoluta dependência dos peritos-médicos e, o que é mais, faz tábula rasa do caráter ético da responsabilidade.

A responsabilidade criminal, com efeito, é problema de ordem jurídica e não médica, como aliás reconheceu o Congresso de Alienistas reunido em Genebra, em 1907, salientando que ao perito médico compete, apenas, pronunciarse sôbre a realidade e a natureza das perturbações mentais dos acusados ${ }^{14}$.

O segundo sistema - o método psicológico - apresenta o defeito de permitir arbítrio na prática judicial, correndose o risco de se admitir um extensivo reconhecimento da irresponsabilidade, contrário ao interêsse social.

De tal modo, o terceiro sistema, ou seja, o método bio-psicológico ou misto, é o que menos inconvenientes apresenta. Por isso tem merecido a preferência de grande parte das legislações penais, inclusive a nossa. Nessas legislações costuma-se mencionar, sintèticamente, os estados nosológicos ou de natureza análoga que excluam ou possam excluir a imputabilidade, fornecendo aos juízes os elementos psicológicos e jurídicos que devem guiá-los na apreciação de tais estados. Torna-se, assim, a questão da imputabilidade, para ser bem resolvida, dependente da colaboração de peritos médicos. Mas, como ela é, sobretudo, jurídica, cabe aos juízes a última palavra. Os laudos periciais servem, apenas, de elementos informadores de sua livre convicção $0^{15}$.

$O$ inconveniente apresentado por êsse sistema está na impossibilidade de encontrar, na situação atual da psiquiatria, fórmulas que, em resumo, compreendam tôdas as situações nosológicas de ordem psiquiátrica que dão lugar a exclusão ou diminuição da -imputabilidade ${ }^{16}$.

14. F́lamínio FÃvero, Medicina Legal, p. 804 (2. ${ }^{\mathrm{a}}$ edição).

15. A. J. Costa e Silva, Códligo Penal (de 1940), p. 179.

16. A. J. CoSta E Silva, ob. cit., p. 181. 
Por isso, na enumeração das causas que acarretam a inimputabilidade, variam grandemente as expressões usadas pelos códigos. $O$ alemão disciplina que: "L'acte punissable n'exist pas lorsque, au temps de sa commission, l'auteur était incapable d'en apprécier le caractère illicite et d'agir en conformité de son appréciation, du fait d'une maladie mentale, d'un trouble pathologique de l'activité mentale ou d'une débilité mentale"17. O Código holandês estatui: "N'est pas punissable celui qui commet un fait que ne peut lui être imputé en raison de son développement insuffisant ou de troubles pathologiques de l'intelligence"18.

O Código Penal suíço fala em "moléstia mental, imbecilidade ou grave perturbação da consciência". De igual modo se expressa o Código peruano, e o argentino faz alusão a "insuficiência das faculdades, por alterações mórbidas das mesmas ou pelo estado de inconsciência"19.

O nosso atual Código Penal fala em "doença mental ou desenvolvimento mental incompleto ou retardado", sendo que essa é considerada uma das fórmulas menos imperfeitas.

Constitui tarefa da psicotapologia forense determinar, em cada caso concreto, se a doença ou o defeituoso desenvolvimento mental produz a incapacidade a que se refere a lei. A punição será excluída se, em virtude dêsses fatôres, o agente fôr inteiramente incapaz de entender o caráter criminoso do ato ou de determinar-se de acôrdo com êsse entendimento.

Cuida também o nosso Código da imputabilidade restrita, uma vez que a doutrina corrente considera a impunidade dos semi-imputáveis como contrária aos fundamentos do atual direito repressivo 20.

A inspiração imediata das disposições relativas aos inimputáveis encontrou-a, o legislador brasileiro, no art. 10 do Código Penal suíço, que assim dispõe: “n'est pas

17. MARC ANCEL, ob. cit., vol. I, p. 19.

18. MARC ANCEL, ob. cit., vol. III, p. 1385.

19. A. J. Costa E Silva, ob. cit., p. 181.

20. A. J. Costa E Silva, ob. cit., p. 183. 
punissable celui qui, étant atteint d'une maladie mentale, d'idiotie ou d'une grave alteration de la conscience, ne possédait pas, ou moment d'agir, la faculté d'aprecier le caractére illicite de son acte ou de se déterminer d'après cette apréciation".

De tal forma, tanto no Código que serviu de modêlo, como no nosso, a imputabilidade, como pressuposto da responsabilidade, se integra plenamente, quando ocorrer: a) certo grau de desenvolvimento mental e conseqüente maturidade psíquica; b) sanidade mental; c) entendimento ético-jurídico; d) faculdade de auto determinação ${ }^{21}$.

Desde que o Direito Penal venceu a fase rudemente objetiva de suas origens, o seu sistema veio a se constituir, tendo-se em vista a idéia de culpabilidade, elemento da estrutura conceitual do crime $^{22}$.

Por isso, desde logo, se destacou na culpabilidade, o momento psicológico pelo qual o autor se faz sujeito ativo do crime. Mas, para isso, é indispensável que o agente seja imputável, isto é, que esteja em condição de entender o caráter criminoso do fato e de determinar-se de acôrdo com êsse entendimento. Só então poderá ser penalmente responsável e estará em condições de receber a punição como conseqüência do ato delituoso que praticou.

Para a Escola Clássica, como já se salientou, a responsabilidade penal era decorrência da imputabilidade moral, enquanto que, para o positivismo penal, o conceito de imputabilidade desaparece, absorvido pelo conceito de responsabilidade social.

Mas, entre êsses limites extremos, encontram-se correntes mistas ou eclèticas, sobressaindo-se, entre elas, a teoria de TARDE, baseada na identidade pessoal e na se semelhança social, a de VoN List, sôbre a normalidade da capacidade de dirigir-se segundo os motivos, a de Impallo-

21. Salgado Martins, Sistema de Direito Penal Brasileiro, p. 276.

22. Aníbal Bruno, Direito Penal, vol. I, tomo 2., p. 407. 
MEnı, sôbre a intimibilidade do delinqüente, a de ManzinI sôbre a capacidade ou personalidade do Direito Penal.

De tal forma, a doutrina da imputabilidade e, por conseqüência, da responsabilidade, modernamente, pode ser dividida em três grupos.

O primeiro grupo é constituído por aquêles que propugnam pela intangibilidade do instituto da imputabilidade, justificando-a através do velho conceito da responsabilidade moral.

O segundo grupo é constituído pelos que negam essa intangibilidade, porque negam a liberdade moral e concebem o instituto da imputabilidade como um conceito teórico que deve ser substituído pelo conceito da responsabilidade legal ou pelo critério da responsabilidade social, tudo fundado sôbre a reação social contra o delito.

Um terceiro grupo é constituído pelos adeptos da teoria intermédia que coloca a imputabilidade sôbre a elaboração dos elementos psicológicos conscientes, fixando-se no critério de intimidação do delinqüente, considerando-o capaz de sentir a intimidação psicológica.

O primeiro grupo é formado sob a inspiração de tendências racionalistas puras; o segundo funda o princípio geral determinante da imputabilidade na voluntariedade do fato delituoso; o terceiro, por fim, coloca a imputabilidade sob o princípio da intimidação ${ }^{23}$.

A variedade de teorias que procuram justificar a imputabilidade está a demonstrar que o problema permanece longe de encontrar soluções pacíficas. Mas, de qualquer modo, a maior parte das concepções reconhece que o indivíduo é responsável por seus atos e por sua conduta. Sua responsabilidade será tanto maior quanto mais nítida fôr a sua capacidade de conhecer o ambiente que o cerca $^{24}$.

23. AlFREdo GrannitraPaNi, La ragione humana della Imputabilità e Responsabilità Penale, p. 368.

24. Smirnov, Leontiev e outros, Psicologia, ed. Grijalbdo, Mexico, p. 387 . 
As legislações modernas coincidem em conceituar a jmputabilidade como a capacidade de entender e de querer. Sem dúvida o organismo e a natureza humana são determinados por tôdas as fòrças que sôbre êles atuam. Mas, êsse complexo organismo é, certamente, centro emissor de energias que produzem estímulos de amplas conseqüências.

Além disso, trata-se de organismo altamente autônomo, mais do que qualquer outro. Portanto, é possivel considerálo, com toda razão, como causa eficiente das conseqüências dos atos que dêle emanam ${ }^{25}$.

Portanto, o homem é algo mais do que simples joguete das circunstâncias. Possui uma vontade, que pode ser objeto de intluências, e êste fato constitui a própria razão de ser da pena. Se nâo fôsse possível influenciar-se a vontade por meio da pena, esta não seria mais do que uma mera crueldade, como já fêz notar HuME ${ }^{26}$.

Dêsse modo a alternativa entre uma responsabilidade social ou objetiva e uma responsabilidade moral é, hoje, insustentável. É um falso dilema, porque o direito é uma instância de responsabilidade autônoma, perfeitamente caracterizada. O conceito de responsabilidade deve ser entendido como um conceito jurídico, não se pensando em restabelecer a chamada responsabilidade moral. Essa solução supunha, em ambas as partes, uma ontologia rudimentar para a qual só é dado conhecer um mundo físico e um mundo moral, de modo que o direito só teria lugar em um dêsses compartimentos. 0 direito, ao contrário, está situado entre os produtos da cultura humana, como a ciência, a técnica, a arte, etc., dentro de um plano espiritual no qual a moral também se encontra.

$O$ direito tem as suas próprias exigências e a responsabilidade jurídica apresenta uma estrutura própria e, sobretudo, uma dinâmica específica, desencadeante da

25. M. Parmelle, ob. cit., p. 372.

26. W. A. BONGER, Introdución a la Criminologia, ed. esp., p. 69. 
coação, o que torna perigoso, além de incorreto, chamá-la de responsabilidade moral ${ }^{27}$.

O êrro da concepção positiva está em erigir a periculosidade do agente como critério da responsabilidade, desprezando as suas condições subjetivas, que não são levadas em conta para determinar a sua capacidade de imputação. A falta da concepção clássica está em se deixar prender a um conceito puramente racional, divorciado da experiência histórica.

A ação humana só assume características de delito quando atua em contraposição ao interêsse jurídico. 0 crime, antes da sua interpretação antropológica, tem um conteúdo social e jurídico.

Não é uma determinada entidade nosológica que faz o homem delinqüente. Ela pode, apenas, explicar os impulsos mórbidos de sua personalidade, traduzidos em reação anti-social, mas nada significa se não fôr tomada como referência a determinada ordem jurídica ${ }^{28}$.

A responsabilidade, pois, tem um conteúdo de natureza jurídica, que reside na capacidade que tenha o agente em distinguir aquilo que é virtude daquilo que é vício, em distinguir o lícito do ilícito penal.

27. Sebastião Soler, Exposição de motivos do ante-projeto de Código Penal argentino.

28. Salgado Martins, ob. cit., p. 372. 